\title{
PET/MRI in Breast Cancer
}

\author{
Akshat C. Pujara, MD, ${ }^{1 \star}$ Eric Kim, MD, ${ }^{2}$ Deborah Axelrod, MD, ${ }^{3}$ and \\ Amy N. Melsaether, MD²
}

\section{CME Information: PET/MRI in Breast Cancer}

If you wish to receive credit for this activity, please refer to the website: www. wileyhealthlearning.com

\section{Educational Objectives}

Upon completion of this educational activity, participants will be better able to evaluate the strengths, limitations, and future directions of PET/MRI in the evaluation of breast cancer, as compared with prior to the activity.

\section{Activity Disclosures}

No commercial support has been accepted related to the development or publication of this activity.

\section{Faculty Disclosures:}

Editor-in-Chief: Mark E. Schweitzer, MD, discloses consultant fees from MCRA and MMI.

CME Editor: Mustafa R. Bashir, MD, discloses research support from GE Healthcare, Madrigal Pharmaceuticals, NGM Biopharmaceuticals, Siemens Healthcare and Taiwan J Pharma, and consultant fees from RadMD.

\section{CME Committee:}

Bonnie Joe, MD, PhD, discloses author royalties from UpToDate.

Tim Leiner, MD, PhD, discloses research grants from Bayer Healthcare and Philips Healthcare.

Shreyas Vasanawala, MD, PhD, discloses research support from GE Healthcare, and founder's equity in Arterys.
Eric Chang, MD, Feng Feng, MD, and Bruno Madore, PhD no conflicts of interest or financial relationships relevant to this article were reported.

\section{Authors:}

Akshat C Pujara MD, Eric Kim MD, Deborah Axelrod MD, Amy N Melsaether MD reported no conflicts of interest or financial relationships relevant to this article.

This activity underwent peer review in line with the standards of editorial integrity and publication ethics. Conflicts of interest have been identified and resolved in accordance with John Wiley and Sons, Inc.'s Policy on Activity Disclosure and Conflict of Interest.

\section{Accreditation}

John Wiley and Sons, Inc. is accredited by the Accreditation Council for Continuing Medical Education to provide continuing medical education for physicians.

John Wiley and Sons, Inc. designates this journal-based CME activity for a maximum of 1.0 AMA PRA Category 1 Credit $^{\mathrm{TM}}$. Physicians should only claim credit commensurate with the extent of their participation in the activity.

For information on applicability and acceptance of continuing medical education credit for this activity, please consult your professional licensing board.

This activity is designed to be completed within 1 hour. To successfully earn credit, participants must complete the activity during the valid credit period, which is up to two years from initial publication. Additionally, up to 3 attempts and a score of $70 \%$ or better is needed to pass the post test. 
Positron emission tomography / magnetic resonance imaging (PET/MRI) is an emerging imaging technology that allows for the acquisition of multiple MRI parameters simultaneously with PET data. In this review, we address the technical requirements of PET/MRI including protocols and tracers, the potential of integrated localized breast PET/MRI exams, and possible applications of whole-body PET/MRI in breast cancer patients. Currently, PET/MRI can be performed on sequential and integrated PET/MRI scanners but, as not all practices can access these dedicated machines, several studies look at PET and MRI exams that are performed separately on separate scanners within a short time frame. This practice likely provides similar clinical data, although exact colocalization for iso-voxel analysis, currently performed only in research, is not possible. In PET/MRI, the MRI sequences are flexible and can be customized according to the aim of the exam. The most commonly used radiotracer is ${ }^{18} \mathrm{~F}-\mathrm{FDG}$; however, tracers that image hypoxia and drug targets such as estrogen receptors and HER2 are in development and may increase the utility of PET/MRI. For dedicated breast PET/MRI, a potential advantage over standard breast MRI alone may be the complementary sensitivities of MRI for extent of disease within the breast and PET for axillary and internal mammary nodal metastases. Moreover, layers of multiparametric MRI and PET metrics derived from the index lesion are being investigated as predictors of response to neoadjuvant therapy. These data may eventually be able to be quantified and mined in a way that furthers radiomics and also precision medicine. Finally, in whole-body imaging of breast cancer patients, single-institution studies have found that PET/MRI detects more metastases than PET at about half the radiation dose, although a survival benefit has not been shown. For now, whole-body PET/MRI in breast cancer patients may be most relevant for young patients who may undergo serial surveillance exams.

Level of Evidence: 3

Technical Efficacy: Stage 2

J. MAGN. RESON. IMAGING 2019;49:328-342.

P ositron emission tomography (PET) and magnetic resonance imaging (MRI) have been combined into integrated PET/MRI, an imaging tool that acquires both the metabolic data of PET and, most often, the high contrast morphological data of MRI as part of a single exam. Advanced MR techniques such as proton MR spectroscopy (MRS) and diffusion-weighted imaging (DWI) can also be run simultaneously with PET acquisition, broadening potential clinical oncologic and research applications.

MRI and PET imaging are both commonly used in breast cancer. PET imaging in breast cancer is most often used in the form of PET computed tomography (CT) with fluorine-18 fludeoxyglucose $\left({ }^{18} \mathrm{~F}-\mathrm{FDG}\right)$ to assess distant metastatic disease and to look for and monitor recurrent disease. ${ }^{1}$ Positron emission mammography (PEM) is also used in breast imaging, but this system has a higher spatial resolution and smaller field of view than whole-body PET imaging and is not currently integrated with MRI for breast imaging. ${ }^{2}$ As such, PEM is not discussed in this review.

Dynamic contrast-enhanced (DCE) MRI is both a morphologic and a functional imaging tool that, in addition to providing morphologic data, depicts areas of increased blood flow, an early characteristic of breast cancers and an obligate characteristic of biologically relevant breast cancers. DCE MRI is the most sensitive tool for breast cancer screening ${ }^{3,4}$ and is also used to assess the extent of disease in patients with known breast cancers and to monitor breast cancers during and after neoadjuvant therapy. ${ }^{5}$ Preliminary investigations of advanced perfusion, diffusion, spectroscopy, and sodium imaging MR techniques are under way to further characterize breast cancers. Eventually, these tools may help to match specific imaging characteristics with disease characteristics and behavior (radiomics) and with genetic information (radiogenomics).
Breast MR cannot always differentiate benign from malignant enhancement and cannot identify locally advanced disease in morphologically normal lymph nodes. PET breast imaging has demonstrated increased specificity as compared with $\mathrm{MR}^{6,7}$ and high sensitivity for axillary lymph node metastases. ${ }^{8,9}$ Fusing separate PET and MR breast imaging has been looked at as a means to preserve the sensitivity of MR, decrease false-positive exams, and increase axillary nodal metastasis sensitivity. ${ }^{10-13}$ This field was limited by the logistic limitations of requiring patients to undergo multiple exams and the technical and temporal limitations of fusing the two exams. Now, however, PET and MRI can be acquired simultaneously and coregistered, allowing radiologists to evaluate not only how the combination of exams can improve sensitivity and specificity, but also to put together exams with multiple parameters (eg, PET, DCE MRI, DWI MRI, MRS). With multiparametric imaging, radiologists can assess layers of parameters voxel-by-voxel, and use this information to characterize tumor heterogeneity and to search for multiparametric hints at predicting clinical outcomes.

\section{TECHNICAL}

PET and MR fusion became clinically viable with advances in PET detectors. Traditional PET photomultiplier tubes used in PET/CT systems are not compatible with the high magnetic fields integral to MRI, and photomultiplier tubes are too large to fit into an MR gantry. The development of MRI-compatible solid-state PET detectors facilitated placing PET and MR scanners in the same space. Two nonintegrated PET/MRI systems scan patients sequentially, with patients undergoing PET or PET/CT and MRI separately in the same room while the patient's position is unchanged. The 
sequential PET/CT and MRI system allows for CT-based attenuation correction. Although these systems provide improved colocalization over completely separate MR and PET exams, they do not allow for dynamic imaging on both systems. Integrated, simultaneous PET/MRI depends on solid-state semiconductor PET detectors, such as avalanche photodiodes, which are much smaller than conventional PET detectors ${ }^{14}$ and can be placed inside an MR gantry. This type of integrated system performs both exams at the same time, providing a shortened exam time for patients and the opportunity to visualize dynamic processes with both modalities. An integrated system, or any system without CT, requires MR-based attenuation correction, most commonly achieved through a Dixon sequence-based segmentation method. ${ }^{7,14-16}$

MR-based attenuation correction for breast and body PET/MRI has been validated. ${ }^{17-24}$

\section{Radiotracers}

There are only two US Food and Drug Administration (FDA)-approved PET radiotracers used in breast cancer imaging, ${ }^{18} \mathrm{~F}$-FDG and fluorine 18 -sodium fluoride $\left({ }^{18} \mathrm{~F}-\mathrm{NaF}\right)$. ${ }^{18} \mathrm{~F}$-FDG images cellular glucose uptake and is highly sensitive for breast cancers and for breast cancer metastases in a wide range of organs. ${ }^{23}{ }^{18} \mathrm{~F}-\mathrm{FDG}$ has some limitations, including lower sensitivity for lobular breast cancers, ${ }^{25,26}$ ductal carcinoma in situ (DCIS), ${ }^{26}$ and, as the reconstructed spatial resolution of PET is $5-6 \mathrm{~mm}$ at full-width halfmaximum, ${ }^{1}$ for small, subcentimeter tumors. ${ }^{27}$ Conversely, ${ }^{18} \mathrm{~F}$-FDG can show increased uptake in benign breast processes including common entities like fibrocystic changes, fibroadenomas, and fat necrosis. ${ }^{28,29}$

${ }^{18} \mathrm{~F}-\mathrm{NaF}$ is a bone-specific radioisotope that has been investigated in breast cancer patients. ${ }^{30,31}$ Piccardo et $\mathrm{al}^{30}$ demonstrated that in the setting of PET/CT, ${ }^{18} \mathrm{~F}-\mathrm{NaF}$ had a higher sensitivity for osseous metastatic disease than ${ }^{18} \mathrm{~F}$-FDG (100\% vs. $72 \%$ ), but that only a negative ${ }^{18} \mathrm{~F}$-FDG PET/CT was predictive of overall survival, suggesting that ${ }^{18} \mathrm{~F}$-FDG activity is more closely linked to biologically active metastatic disease. That study supports the idea that skeletal ${ }^{18} \mathrm{~F}$-FDG uptake principally occurs in breast cancer cells, while skeletal ${ }^{18} \mathrm{~F}-\mathrm{NaF}$ uptake is reflective of bone remodeling and associated blood flow. ${ }^{32}$

Targeted treatments are administered for estrogen receptor (ER)-positive and human epidermal growth factor receptor 2 (HER2)-positive tumors. Although biopsies provide receptor expression information, breast cancers are heterogeneous, and biopsy may not always demonstrate the presence of a receptor that is present. Further, breast cancer receptor expression can change over time and in response to treatment, both in the primary tumor and in metastases. Hormone receptor and HER2-targeted radiotracers ${ }^{33-37}$ are being investigated and may eventually allow for noninvasive dynamic, optimized therapy throughout breast cancer treatment. In addition, novel radiotracers targeting hypoxia may be useful in therapeutic planning, as hypoxic tumors can undergo mutations that increase resistance to chemotherapy and potentiate metastases. ${ }^{38-40}$ One such tracer, ${ }^{18} \mathrm{~F}$ fluoromisonidazole $\left({ }^{18} \mathrm{~F}\right.$-FMISO) accumulates in hypoxic cells with nitroreductase enzymes and has been shown to predict clinical resistance to antihormone therapy. ${ }^{41}$

\section{Protocol}

As for a routine PET/CT exam, the patient is given a radiotracer (typically $555 \mathrm{MBq}{ }^{18} \mathrm{~F}-\mathrm{FDG}$ ) intravenous (IV) injection after fasting for at least 4 hours. The patient then rests for 45 minutes in a dark room. For a breast PET/MRI exam, a dedicated breast coil is used and the patient is positioned prone. MRI sequences are then run simultaneously with the acquisition of PET data and gadolinium is administered IV after precontrast imaging at the normal weight-based dose. It is recommended that the PET data be collected for at least 2 minutes, although times from $3 \frac{1}{2}$ to 15 minutes have been reported. ${ }^{19,42,43}$ MRI sequences can vary, including the sequences recommended by the American College of Radiology ${ }^{5}$ or can be customized; for example, to include abbreviated breast MRI sequences (a single pre- and postcontrast $T_{1}$-weighted image set) and/or DWI and MRS.

Whole-body PET/MRI uses the same radiotracer (typically ${ }^{18}$ F-FDG) dose, fasting time, and resting time. The exam, however, is performed with supine positioning and head and body matrix coils. The exam is split into stations, such as head, neck, chest, abdomen, pelvis, and thighs, and can be acquired either from caudal to cranial or the reverse. These stations can then be combined into a single image set as part of postprocessing. PET data should be acquired for at least 2 minutes per station (or for the entire duration of MRI at each station). The authors scan from the thighs through the vertex, with a gadolinium injection during the abdomen station to see contrast in the liver and to facilitate postcontrast evaluation of the brain. In breast cancer patients, DCE MRI has been shown to best detect breast and brain lesions, DWI has outperformed DCE MRI for liver and bone metastases, and PET has had high sensitivity for lymph node metastases. ${ }^{44}$ Suggested sequences are listed in Table 1.

\section{INDEX LESION EVALUATION}

\section{Benign vs. Malignant}

DCE breast MRI has a high sensitivity, reported at up to $100 \%,{ }^{3,4}$ and a positive predictive value above $35 \%{ }^{45}$ $\mathrm{PET} / \mathrm{CT}$ is not routinely performed for breast cancer detection because is it not adequately sensitive, ${ }^{46-50}$ especially for lobular cancers ${ }^{48}$ and for cancers less than $1 \mathrm{~cm}^{50}$ Authors have investigated whether combining DCE MRI and PET data in the breast can improve the diagnostic accuracy for 
TABLE 1. Whole-Body PET/MRI in Patients with Breast Cancer: Suggested MRI Sequences by Imaging Station

\begin{tabular}{|c|c|c|c|}
\hline Station & T1-weighted sequences & T2-weighted sequences & Notes \\
\hline All echo T2 & $\begin{array}{l}\text { Coronal 3D gradient-echo For } \\
\text { DIXON-based } \mu \text {-map }\end{array}$ & Coronal high-speed turbo-spin & disease \\
\hline Bone/Pelvis & $\begin{array}{l}\text { Radial non-contrast 3D Non-contrast T1 } \\
\text { for fat- gradient-echo, or T1 Dixon } \\
\text { containing lesions }\end{array}$ & $\begin{array}{l}\text { Axial high-speed turbo-spin } \\
\text { echo or Axial } 3 \text { b-value DWI }\end{array}$ & \\
\hline Liver/Abdomen & $\begin{array}{l}\text { Radial 3D fat-suppressed Fat-saturated T2 } \\
\text { for fat- gradient-echo, with or without } \\
\text { containing lesions contrast }^{\mathrm{a}}\end{array}$ & $\begin{array}{l}\text { Axial high-speed turbo-spin echo, } \\
\text { Axial } 3 \text { b-value DWI, } \\
\text { Axial fat- saturated T2 }\end{array}$ & \\
\hline Lung/Thorax & $\begin{array}{l}\text { Radial 3D fat-suppressed gradient-echo } \\
\text { with or without contrast }\end{array}$ & & \\
\hline Brain/Head & $\begin{array}{l}\text { Post-contrast magnetization Pre-contrast } \\
\text { for prepared rapid gradient-echo, or } \\
\text { hemorrhage }{ }^{b} \text { pre-contrast } 3 \mathrm{D} \\
\text { radient-echo }{ }^{\mathrm{b}} \text { FLAIR for leptomeningeal }\end{array}$ & T2 post-contrast FLAIR & \\
\hline
\end{tabular}

breast cancer, ${ }^{6,7,11}$ but have found that the addition of PET often decreases the sensitivity of DCE-MRI.

In a study of 101 benign and malignant breast lesions, Botsikas et $\mathrm{al}^{6}$ compared DCE MRI with qualitative and quantitative ${ }^{18} \mathrm{~F}$-FDG PET/MRI and reported areas under the curve (AUC) of $0.9558,0.8347$, and 0.8855 with MRI, qualitative, and quantitative ${ }^{18}$ F-FDG PET/MRI. ${ }^{6}$ Although the specificity of DCE MRI improved from $67-100 \%$, the authors did not recommend adding PET to MRI because of the compromised sensitivity. ${ }^{6}$ Similarly, adding PET to DCE MRI data decreased sensitivity from $93-88 \%$ in a study of 58 breast lesions by Heusner et al. ${ }^{7}$

However, Bitencourt et al showed that when multiple MR parameters are included in a PET/MR evaluation, 100\% sensitivity could be achieved. ${ }^{46}$ In that study, the authors evaluated 38 lesions, 29 of which were malignant, with DCE MRI, DWI, and ${ }^{18} \mathrm{~F}$-FDG PET. A lesion had to meet one of three criteria: a washout curve on DCE MRI, $\mathrm{ADC}_{\text {min }}$ $<1.00 \times 10 \mathrm{~mm} / \mathrm{s}$, or ${ }^{18} \mathrm{~F}$-FDG uptake above background. The specificity in this study was $55 \%{ }^{46}$ In another multiparametric study, Pinker et al included four parameters: PET, DCE MRI, DWI, and 1hydrogen-MRS, in their evaluation of 78 indeterminate or suspicious breast lesions. ${ }^{51}$ While the authors demonstrated that combining all four parameters would have reduced unnecessary biopsies by $50 \%$ as compared with DCE MRI alone, this extensive exam may not be clinically practical. Figure 1 shows an example of multiparametric imaging of a triple-negative breast cancer. In an investigation of advanced perfusion, Jena et $\mathrm{al}^{52}$ performed a feasibility study, looking at whether the pharmacokinetic DCE-MRI parameters $K_{\text {trans }}$ (a volume transfer coefficient reflecting vascular permeability), $K_{\mathrm{ep}}$ (a flux rate constant), and $V_{e}$ (an extracellular volume ratio) from a high-resolution breast MRI protocol on an integrated $\left[{ }^{18} \mathrm{~F}\right] \mathrm{FDG}$ PET/MRI system could separate benign and malignant lesions as well as those same metrics obtained from a stand-alone 3T scanner. ${ }^{52}$ The authors showed sensitivities of $98.6 \%, 82.9 \%$, and $98.6 \%$ for $\mathrm{K}_{\text {trans }}, \mathrm{K}_{\mathrm{ep}}$, and $\mathrm{V}_{\mathrm{e}}$ for detecting breast cancers, and accuracies of $94.50 \%, 79.82 \%$, and $87.16 \%$, respectively, for these same variables. ${ }^{52}$ These results are improved over their earlier work on a stand-alone $3 \mathrm{~T}$ MRI, ${ }^{53}$ suggesting advanced DCE MRI metrics obtained on an integrated scanner are valid.

\section{Relationships Between PET/MR Metrics and Clinical Features}

Advanced MRI can provide several perfusion and diffusion metrics that have been looked at, together with PET metrics, in efforts to predict clinical features through imaging analyses. Although some authors have seen correlations between PET and MR metrics, as described below, these correlations are not uniform between studies.

METASTATIC DISEASE, K167. Margolis et al evaluated perfusion data $\mathrm{K}_{\text {trans }}, \mathrm{K}_{\mathrm{ep}}$, and $\mathrm{V}_{\mathrm{e}}$, and ${ }^{18} \mathrm{~F}$-FDG PET data standardized uptake value (SUV) and metabolic tumor volume 


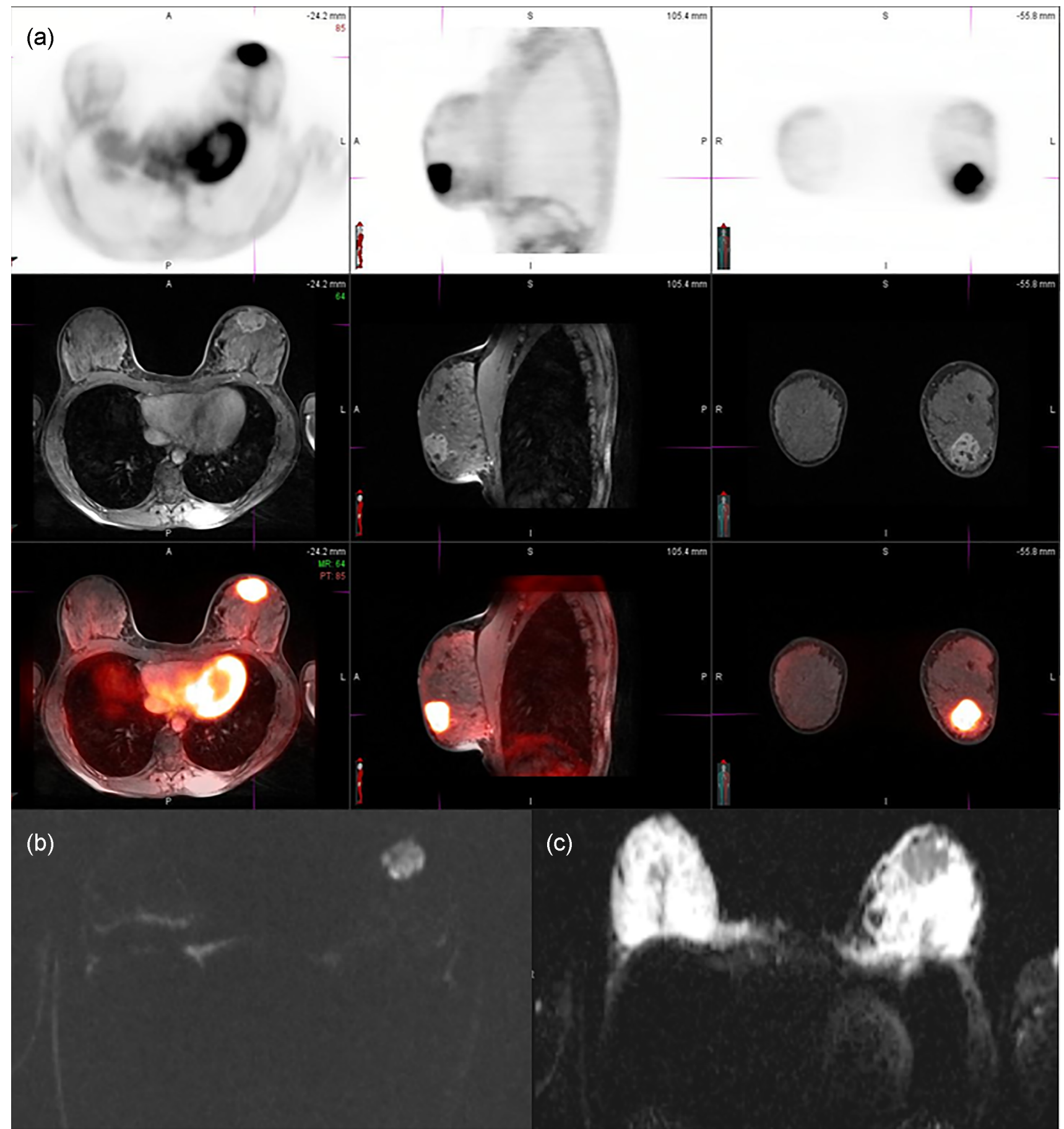

FIGURE 1: A 38-year-old female diagnosed with triple negative invasive ductal carcinoma of the left breast. At the time of the examination, there was no evidence of metastatic disease. (a) The top row is the PET, the middle row is the DCE-MRI, and the bottom row is the fused PET/MRI images. The index lesion is well characterized on these images as an FDG-avid heterogeneously enhancing lesion in the left breast abutting the skin surface. (b) A diffusion-weighted image demonstrates increased signal intensity within the mass. (c) The corresponding ADC map demonstrates decreased signal intensity within the mass consistent with diffusion restriction.

(MTV) in breast cancer patients with and without metastases. ${ }^{54}$ In that study, $\mathrm{K}_{\text {trans }}$ and $\mathrm{SUV}_{\max }$ correlated positively with metastatic disease, whereas $K_{e p}$ correlated negatively. Similarly, tumors with higher levels of Ki67, a marker for cell proliferation, showed a significantly greater $\mathrm{K}_{\text {trans }}$ compared with tumors with lower levels of Ki67. ${ }^{54}$ Data like these suggest the potential for $\mathrm{K}_{\text {trans }}$ and $\mathrm{SUV}_{\max }$ to suggest patients in whom whole-body imaging should be performed to assess for metastatic disease.

TUMOR MARKERS. Catalano et al investigated whether ${ }^{18} \mathrm{~F}$ FDG PET/MR could differentiate between histological phenotypes of breast cancer in 21 patients with invasive ductal carcinoma (IDC). ${ }^{55}$ The authors found that estrogen receptor 
(ER) and progesterone receptor (PR)-negative tumors had higher $\mathrm{SUV}_{\max }$ and $\mathrm{K}_{\mathrm{ep}}$ than ER or PR-positive tumors; that HER2-negative tumors had higher apparent diffusion coefficient $(\mathrm{ADC})_{\text {mean }}, \mathrm{K}_{\mathrm{ep}}$, and $\mathrm{SUV}_{\max }$ values; and that tumors with lower levels of $\mathrm{Ki} 67$ showed lower $\mathrm{ADC}_{\text {mean }}$, but not greater $\mathrm{K}_{\text {trans }}$, as seen in the Margolis et al study. ${ }^{54} \mathrm{PET} / \mathrm{MR}$ markers correlated with immunohistochemical (IHC) phenotype in $62 \%$, a promising beginning. ${ }^{55}$

SURVIVAL. An et al ${ }^{56}$ looked at 67 women with breast cancer with DCE MRI and ${ }^{18}$ F-FDG PET performed separately and demonstrated an inverse relationship between $S_{U} V_{\text {max }}$ and $V_{e}$ and, notably, a negative correlation between metabolic heterogeneity and survival. ${ }^{56}$ These same authors also found a positive correlation between $S U V_{\max }$ and $K_{\text {ep }}$ in nontriplenegative breast cancers (TNBC), but not in TNBC. ${ }^{57}$

$S U V_{\text {MAX }}$ AND ADC. High $S U V_{\max }$ is a marker for tumors with high concentrations of glucose uptake and has been positively correlated with many clinical factors including tumor grade, ${ }^{58-61}$ stage,$^{58}$ size, ${ }^{58-61}$ ER negativity, ${ }^{58-62} \mathrm{PR}$ negativity, ${ }^{58,62}$ HER2 positivity, ${ }^{58,59}$ TNBC, ${ }^{50,61}$ higher Ki67, ${ }^{50,58,62}$ and axillary lymph node positivity. ${ }^{58-61} \mathrm{SUV}_{\max }$ has also been correlated inversely with both progression-free survival and overall survival. ${ }^{60}$ High levels of restricted diffusion are a marker for malignancy and generate low ADC values. Correlations between $\mathrm{ADC}$ values and clinical factors appear less replicable than those between SUVs and clinical markers. For example, ADC has been inversely correlated with ER positivity, ${ }^{61}$ HER2 negativity, ${ }^{60,61}$ tumor size, Ki67 expression, histologic subtype, the presence of axillary metastases and TNM staging. ${ }^{58}$ However, in a study by Karan et al of 70 women with breast cancer, no correlations between ADC median and many of these metrics (size, grade, lymph node status, ER status, HER2 status) were seen. ${ }^{59}$ Several authors have investigated whether $S_{U} V_{\max }$ and $\mathrm{ADC}$ are inversely related and have obtained mixed results, ${ }^{50,58-61}$ suggesting that these markers reflect two separate and not necessarily related properties of breast cancers.

\section{LOCOREGIONAL STAGING}

Locoregional staging of breast cancer includes primary tumor size, assessment of multifocality, and detection of nodal disease in the axillae and internal mammary (IM) chains. Accurate locoregional staging is important for surgical and oncologic planning as well as posttreatment surveillance.

\section{Tumor Size and Multifocality}

While PET/MRI appears to outperform PET/CT, PET/MRI does not appear to offer a benefit over the current standard, MRI alone, in assessing tumor size or multifocality, the presence of at least one additional malignant focus less than $5 \mathrm{~cm}$ from the index lesion. Multifocality is associated with an increased likelihood of nodal disease ${ }^{64}$ and may be associated with an increased risk of recurrence after lumpectomy. ${ }^{65} \mathrm{~A}$ study by Grueneisen et al of PET/MRI vs. PET/CT and MRI alone in 49 patients with 50 breast cancers demonstrated that PET/MRI and MRI alone correctly identified the T-stage of breast cancers a significantly higher number of times than PET/CT (41/50 [82\%] PET/MRI and MRI alone vs. $34 / 50[68 \%]$ PET/CT; $P<0.05) .{ }^{8}$ In the same study by Grueneisen et al, PET/MRI and MRI alone correctly identified multifocal/multicentric disease in $8 / 9$ patients, compared with $5 / 9$ by PET/CT. Similar to Grueneisen et al, Goorts et al found that PET/MRI and MRI alone were equivalent for assessing breast tumor size and multifocality in 40 patients with breast cancer. ${ }^{66}$

Two additional studies demonstrated MRI to be more sensitive than PET/CT for the detection of multifocal breast cancer, while PET/CT demonstrated higher specificity. Jung et $\mathrm{al}^{48}$ compared the two modalities among 105 biopsy-proven breast cancers. MRI detected all 105 primary tumors, while PET/CT identified 85/105 (81.0\%) primary tumors. Additional foci of malignancy were present in the same breast in 25 cases at surgical pathology. The authors reported that the sensitivity of MRI for detecting these ipsilateral lesions was significantly higher than PET/CT ( $P$ \&le; 0.001), while the specificity of PET/CT was superior to that of MRI (P \&le; 0.008). ${ }^{48} \mathrm{~A}$ similar study by Ergul et al reported that in 24 patients with earlystage breast cancer, the sensitivity and specificity of PET/CT and MRI for the detection of multifocality were $67 \%$ vs. $78 \%$ and $100 \%$ vs. $53 \%$, respectively. ${ }^{9}$ Finally, in comparing PET imaging alone vs. MRI alone, Taneja et al identified multifocal/multicentric disease in $21 / 36$ patients. MRI detected a significantly higher number of satellite lesions compared with PET (35 vs. $17, P=0.001$ ); however, four MRI-detected satellite lesions proved to be false positives at pathology. ${ }^{43}$

\section{Axillary and Internal Mammary Lymph Nodes}

In contrast to tumor size and extent, most, but not all, studies indicate that PET-based imaging is more sensitive than MRI for the detection of axillary metastases and limited studies show PET and MRI have similar sensitivity for internal mammary nodes. In Grueneisen et al's ${ }^{8}$ cohort of 49 patients, 18 patients had axillary disease. The sensitivity for axillary nodal status was $78 \%$ for PET/CT, $78 \%$ for PET/MRI, and $67 \%$ for MRI alone; these differences were not statistically significant, likely due to the relatively small number of patients. PET/CT also demonstrated a slightly superior specificity of $94 \%$ for axillary disease, compared with $90 \%$ for PET/MRI and $87 \%$ for MRI alone. ${ }^{8}$ Among the 24 patients in Ergul et al's ${ }^{9}$ series, 15 patients had axillary involvement diagnosed by axillary lymph node dissection. The sensitivity of PET/CT for axillary metastasis was $67 \%$, compared with 


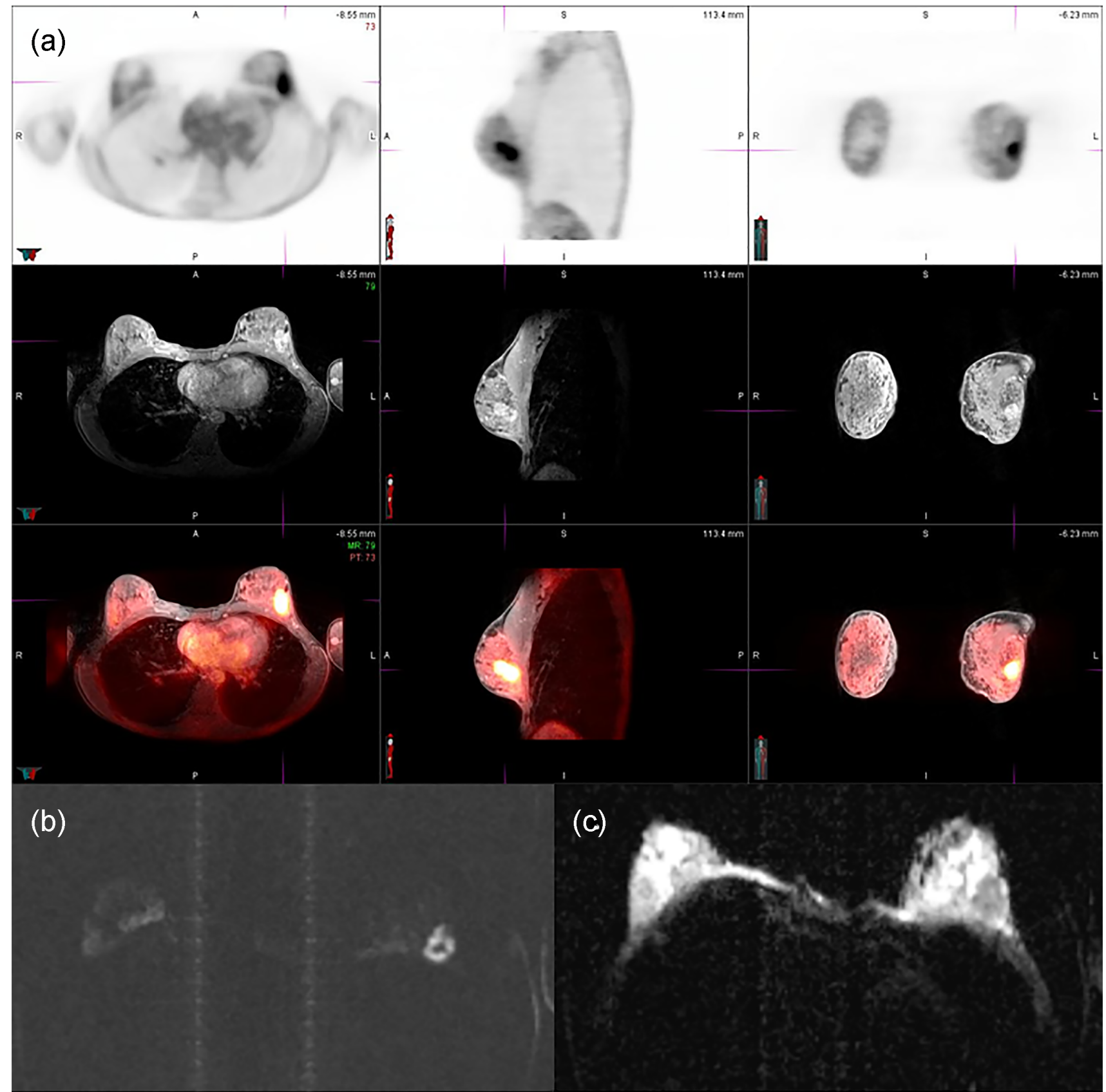

FIGURE 2: A 37-year-old female with left breast invasive ductal carcinoma and no evidence of distant metastatic disease. The patient proceeded to complete a course of neoadjuvant chemotherapy. PET/MRI was performed at the time of diagnosis and then following completion of chemotherapy. (a) Pre-neoadjuvant PET/MRI. The top row is the PET, the middle row is the DCE-MRI, and the bottom row is the fused PET/MRI images. The index lesion is well characterized on these images as an FDG-avid heterogeneously enhancing lesion in the left breast. (b) A diffusion-weighted image demonstrates increased signal intensity within the mass. (c) The corresponding ADC map demonstrates decreased signal intensity within the mass consistent with diffusion restriction. (c) Postneoadjuvant PET/MRI. The top row is the PET, the middle row is the DCE-MRI, and the bottom row is the fused PET/MRI images. Following chemotherapy, there is mild increased signal around the biopsy clip on MRI (white arrow), but no FDG activity on PET and no abnormal signal on DWI or the ADC map (e,f), consistent with the complete pathological response confirmed at excision.

47\% for MRI. The specificity of PET/CT for axillary nodal disease was also higher than MRI, $89 \%$ vs. $78 \%$, respectively. ${ }^{9}$ Notably, the CT portion of PET/CT appears critical to the sensitivity of staging the axilla using PET: without CT, the sensitivity of PET alone for the presence of axillary metastasis has been reported at $60 \%$ by Taneja et al compared with 93.3\% for MRI alone. The specificity of both PET alone and
MRI alone for axillary metastases was $91 \%$ in that study. ${ }^{43}$ Botsikas et $\mathrm{al}^{6}$ evaluated the performance of PET/MRI vs. MRI alone for the detection of axillary, IM, and supraclavicular lymph nodes, and reported combined results in 58 patients with breast cancer. Contrary to the studies described previously, MRI alone demonstrated increased sensitivity of $88 \%$ vs. $79 \%$ for PET/MRI, although this 


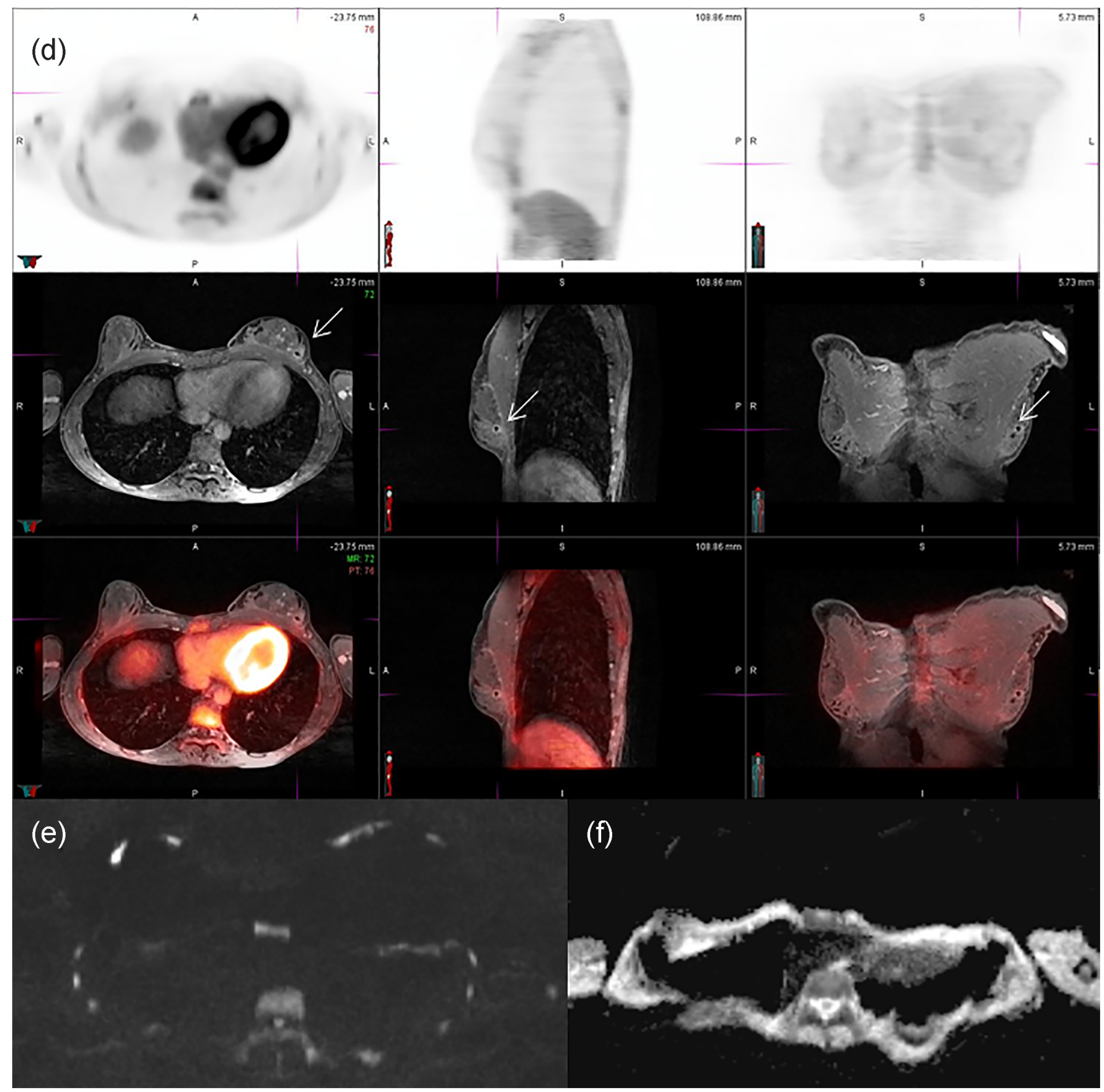

FIGURE 2: Continued

difference was not statistically significant. Specificity was also not significantly different, reported as $98 \%$ for MRI and $100 \%$ for PET/MRI. ${ }^{6}$

Regarding changing axillary nodal status, Goorts et al reported one case of axillary downstaging and one case of axillary upstaging by PET/MRI compared with conventional imaging. ${ }^{66}$ One study evaluated the impact of dedicated axillary PET/MRI on axillary nodal status in 12 patients with clinically positive axillary nodal disease. In that study, axillary PET/MRI changed nodal status in $40 \%$ of patients compared with ultrasound, in $40 \%$ of patients compared with contrast-enhanced MRI, and in $22 \%$ of patients compared with PET/CT. ${ }^{67}$
In addition to staging the axilla, cross-sectional imaging affords evaluation of the IM chains. The identification of IM adenopathy is important, as this finding is associated with a poorer prognosis and may warrant more aggressive treatment. ${ }^{68,69}$ While MRI is increasingly performed to assess the extent of disease following a new diagnosis of breast cancer, ${ }^{70}$ few studies have evaluated the performance of MRI for the detection of IM metastasis, let alone compared MRI with PET-based imaging in this context. In 1999, Kinoshita et al reported a sensitivity of $93.3 \%$ and a specificity of $89.3 \%$ among 43 MRI-detected IM nodes in 16 patients. $^{71}$ In the above-mentioned study of 40 patients by Goorts et al, PET/MRI detected one abnormal IM node not initially seen 


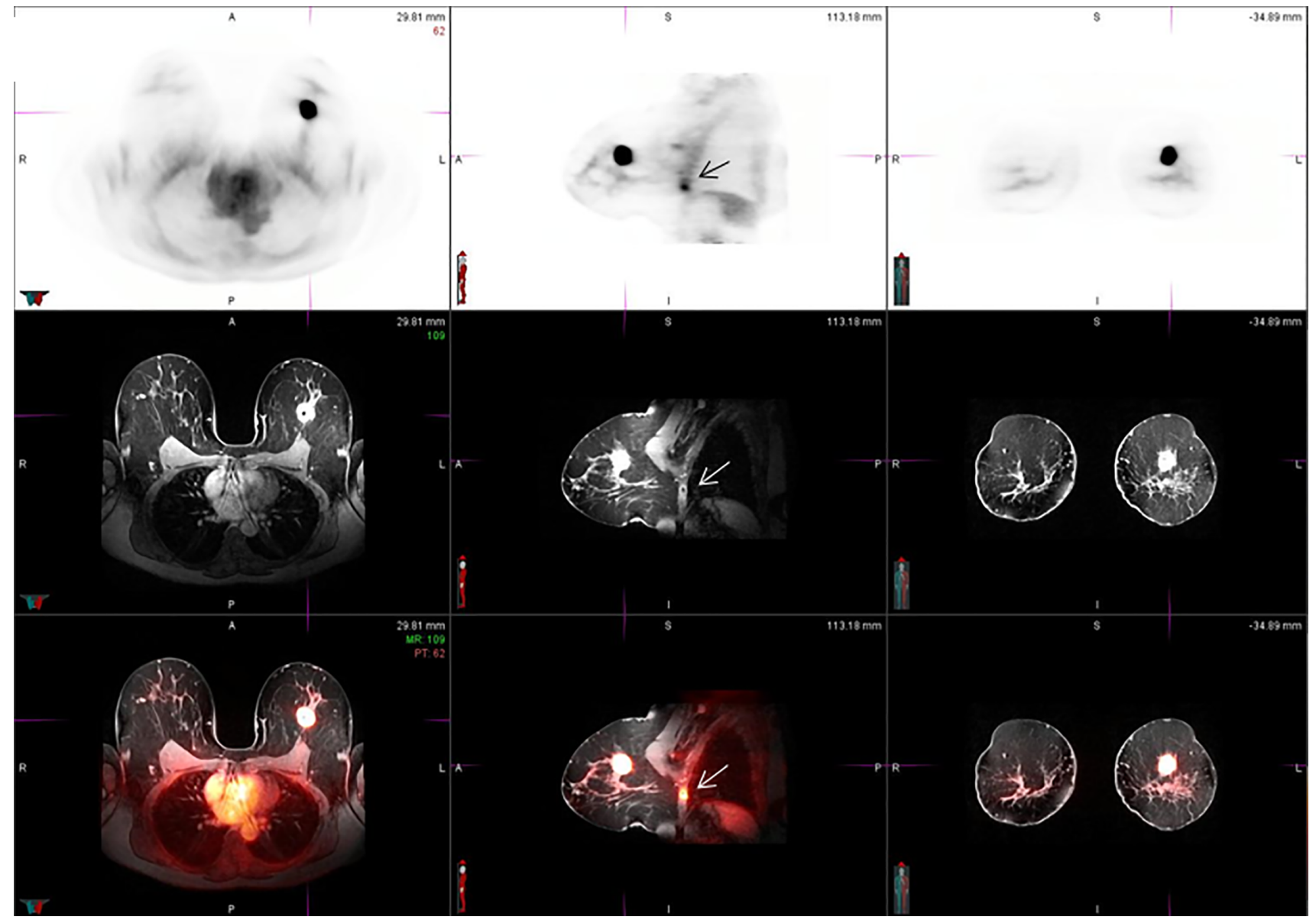

FIGURE 3: A 62-year-old female with a left breast invasive ductal carcinoma with positive left axillary lymph nodes. Whole-body $\mathrm{PET} / \mathrm{MR}$ detected distant metastatic disease in this patient that was not previously diagnosed. The top row is the PET, the middle row is the DCE-MRI, and the bottom row is the fused PET/MRI images. The index lesion is well characterized on these images as an FDG-avid avidly enhancing mass in the left breast. An unexpected rib metastasis is seen enhanced on DCE MRI and is FDG-avid on PET (arrow).

on MRI alone and increased diagnostic confidence in three other cases of IM metastases. ${ }^{66}$ Jochelson et al compared the prevalence of IM adenopathy identified by MRI with that by PET/CT. MRI detected IM disease in $14 / 90(16 \%)$ patients, vs. $13 / 90(14 \%)$ patients by PET/CT $(P=0.317) .{ }^{69}$ The similar performance between PET/CT and MRI for IM nodes and the superiority of PET/CT over MRI for axillary nodes suggest a role for PET in the complete locoregional staging of breast cancer.

\section{NEOADJUVANT THERAPY}

Predicting breast cancer response to chemotherapy is a field of particular interest for PET/MRI. With the emerging field of radiomics, large volumes of quantitative features can be pulled from both PET and MR images and converted into data. ${ }^{72}$ These data can be mined and shared and, over time, may lead to discovery of certain PET/MR radiomic signatures that can help determine optimal therapies for individual breast cancers, such as which drugs will be most effective and whether to begin treatment with chemotherapy or surgery. Such signatures can be automatically derived from images, as demonstrated by Drukker et $\mathrm{al}^{73}$ who, in a study of 143 women who underwent breast cancer treatment, showed that a near completely automatically extracted data point called most enhancing tumor volume (METV) predicted recurrence with similar accuracy to a semimanual method published by Hylton et al. ${ }^{74}$ Below are examples of investigations into the clinical relevance of several PET- and MRI-based metrics that could eventually contribute to radiomics.

\section{Response Prediction}

Cho et al performed ${ }^{18}$ F-FDG PET/MRI in 26 breast cancer patients before and after the first round of chemotherapy and evaluated qualitative MRI parameters as well as quantitative PET and MRI parameters. ${ }^{75}$ While the qualitative MRI parameters were not found to be different between pathologic complete responders and pathologic noncomplete responders, reductions in total lesion glycolysis (TLG) and signal enhancement ratio (SER) were different between the two groups. Separately, the specificity (for pathologic complete response) of $\mathrm{TLG}_{30 \%}$ was $100 \%$ and of SER was $71.4 \%$ and 
TABLE 2. Whole-body PET/MRI versus PET/CT for the detection of organ-specific metastases

\begin{tabular}{|c|c|c|c|c|c|c|}
\hline \multirow[t]{2}{*}{ Study ${ }^{a}$} & \multicolumn{3}{|l|}{$\begin{array}{l}\text { Primary } \\
\text { Cancer }\end{array}$} & \multicolumn{3}{|l|}{ Metastatic Site } \\
\hline & & Liver & Bone & Lung & Pleura & Lymph nodes \\
\hline Beiderwellen $^{93}$ & Various & & $\mathrm{n}=48 ; 48,45$ & & & \\
\hline Drzezga $^{22}$ & Various & $\mathrm{n}=11 ; 9,11$ & $\mathrm{n}=14 ; 14,14$ & $\mathrm{n}=15 ; 15,15$ & & $\mathrm{n}=27 ; 27,27$ \\
\hline Eiber $^{94}$ & Various & & $\mathrm{n}=90 ; 86,86$ & & & \\
\hline Heusch $^{23}$ & Various & & & & & $\mathrm{n}=13 ; 13,11$ \\
\hline Huellner $^{24}$ & Various & & & $\mathrm{n}=17 ; 17,17$ & & $\mathrm{n}=74 ; 74,74$ \\
\hline Jeong $^{95}$ & Various & $\mathrm{n}=1 ; 1,1$ & $\mathrm{n}=11 ; 11,11$ & & & \\
\hline Melsaether ${ }^{44 b}$ & Breast & $\mathrm{n}=40 ; 36,29$ & $\mathrm{n}=107 ; 103.5,98$ & $\mathrm{n}=23 ; 18.5,22.5$ & $\mathrm{n}=16 ; 16,16$ & $\mathrm{n}=60 ; 57,54$ \\
\hline Pace $^{19}$ & Breast & & $\mathrm{n}=11 ; 11,11$ & $\mathrm{n}=3 ; 3,3$ & & $\mathrm{n}=35 ; 35,35$ \\
\hline Schäfer ${ }^{96}$ & Pediatric & $\mathrm{n}=5 ; 5,5$ & $\mathrm{n}=4 ; 4,4$ & & & $\mathrm{n}=28 ; 28,28$ \\
\hline \multicolumn{7}{|c|}{ 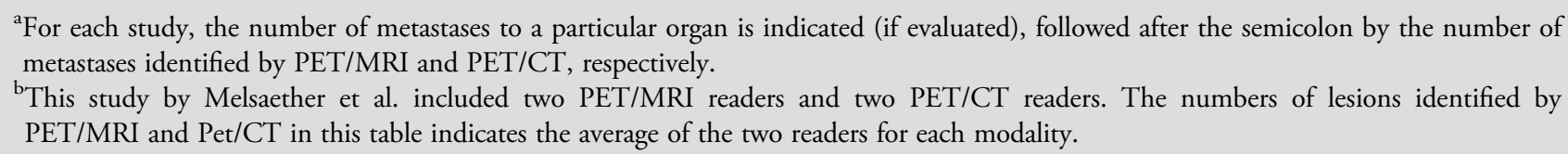 } \\
\hline
\end{tabular}

the sensitivity for predicting pathologic noncomplete response was $63.2 \%$ and $84.2 \%$, respectively. Highlighting the synergistic potential or PET and MRI, the combined sensitivity was $100 \%$ and specificity was $71.4 \%$.

Wang et al also investigated the synergy between PET and MRI parameters in predicting response to chemotherapy. ${ }^{76}$ In their study of 14 women with breast cancer, women underwent scanning before and after the first or second cycle of treatment. They found that \%change in $\mathrm{SUV}_{\max }$, TLG, and peak enhancement ratio (PER) predicted response (AUC $0.898,0.878$, and 0.837 ) and that combined PET and MRI metrics \%change $\mathrm{SUV}_{\max } / \%$ change $\mathrm{ADC}_{\min }$ and \%change TLG/\%change $\mathrm{ADC}_{\text {min }}$ had even higher AUC for differentiating pathologic complete responders from pathologic noncomplete responders (AUC 0.976 and 0.905). ${ }^{77}$ In a study of 93 breast cancer patients, Pengel et al demonstrated that combined PET/MR metrics in concert with clinical data yielded the best accuracy. ${ }^{77}$ While age, breast cancer subtype, \%change in $\mathrm{SUV}_{\max }$ and \%change in largest tumor diameter on MRI predicted near pCR, breast cancer subtype together with changes in $S U V_{\text {max }}$ and tumor diameter provided the highest AUC (0.90). ${ }^{78}$ An et al also showed that combining data, in this case, DWI or DCE-MRI with PET, led to improvement, here in negative predictive value and specificity. ${ }^{78}$ An example of pre- and postchemotherapy imaging is shown in Fig. 2.

Lim et al looked at changes in PET and MR metrics in response to therapy to predict disease-free survival found that patients who met cutoffs for (lesser) declines in both SUV and MR slope had a higher recurrence rate $(78 \%)$ than those who did not (13\%). ${ }^{79}$ Additional studies have shown that both PET and MRI metrics change in response to chemotherapy in pathologic responders, ${ }^{62,80}$ and that changes in $\mathrm{SUV}_{\max }$ may be more accurate than changes in tumor size, but none of these metrics predicts with $100 \%$ accuracy.

Highlighting the potential for advanced integrated PET/MR, advanced MR techniques including sodium $\left({ }^{23} \mathrm{Na}\right)$ MR and 1H-MRSI have also been investigated together with PET. Jacobs et al investigated changes in sodium concentrations with ${ }^{23} \mathrm{Na} \mathrm{MR}$ in six patients before and after initial rounds of treatment and compared with ${ }^{18} \mathrm{~F}$-FDG PET/CT and DCE MRI. ${ }^{81}$ Tissue sodium concentrations increased in all partial responders and decreased in the single nonresponder, whereas MRI tumor volumes and $\mathrm{SUV}_{\max }$ decreased in both partial responders and in nonresponders. Cho et $\mathrm{al}^{82}$ compared 1H-MRSI with PET. The authors found mean percent reductions for total choline, $\mathrm{SUV}_{\text {max }}, \mathrm{SUV}_{\text {peak }}$, and TLG were greater in the pCR group than in the non-pCR group; however, no cutoff values could separate responders from nonresponders.

\section{DISTANT METASTASES}

In patients with breast cancer who require whole-body imaging prior to definitive treatment or for follow-up after 
TABLE 3. Imaging evaluation of extent of disease in breast cancer: A review of the literature comparing imaging modalities

\begin{tabular}{|c|c|c|c|c|c|}
\hline $\begin{array}{l}\text { Author PET } \\
\text { Station }\end{array}$ & $\begin{array}{l}\text { T-stage/ } \\
\text { Tumor size }\end{array}$ & Multifocality & $\begin{array}{l}\text { Axillary } \\
\text { Nodes }\end{array}$ & $\begin{array}{l}\text { Internal } \\
\text { Mammary } \\
\text { Nodes }\end{array}$ & $\begin{array}{l}\text { Distant } \\
\text { Metastases }\end{array}$ \\
\hline $\begin{array}{l}\text { Grueneisen }^{8} \\
\text { Whole body } \\
\text { PET/CT Breast } \\
\text { PET/MRI }\end{array}$ & $\begin{array}{l}\mathrm{PET} / \mathrm{MRI}> \\
\mathrm{PET} / \mathrm{CT}^{\mathrm{b}} \\
\mathrm{PET} / \mathrm{MRI}=\mathrm{MRI} \\
\mathrm{MRI}>\mathrm{PET} / \mathrm{CT}^{\mathrm{b}}\end{array}$ & $\begin{array}{l}\mathrm{PET} / \mathrm{MRI}> \\
\mathrm{PET} / \mathrm{CT}^{\mathrm{a}} \\
\mathrm{PET} / \mathrm{MRI}=\mathrm{MRI}^{\mathrm{a}} \\
\mathrm{MRI}>\mathrm{PET} / \mathrm{CT}^{\mathrm{a}}\end{array}$ & 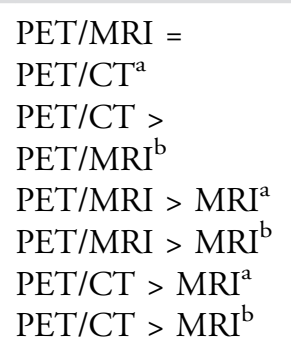 & & \\
\hline $\begin{array}{l}\text { Goorts }{ }^{66} \text { Breast } \\
\text { PET/MRI and } \\
\text { MRI }\end{array}$ & $\mathrm{PET} / \mathrm{MRI}=\mathrm{MRI}$ & $\mathrm{PET} / \mathrm{MRI}=\mathrm{MRI}^{\mathrm{a}}$ & & PET/MRI > MRI ${ }^{\mathrm{a}}$ & \\
\hline $\begin{array}{l}\text { Jung }{ }^{48} \\
\text { Breast MRI, } \\
\text { Whole } \\
\text { body }\end{array}$ & $\mathrm{PET} / \mathrm{CT}$ & $\begin{array}{l}\mathrm{MRI}>\mathrm{PET} / \mathrm{CT}^{\mathrm{a}, \mathrm{b}} \\
\mathrm{PET} / \mathrm{CT}>\mathrm{MRI}^{\mathrm{b}, \mathrm{c}}\end{array}$ & $\begin{array}{l}\mathrm{MRI}>\mathrm{PET} / \mathrm{CT}^{\mathrm{a}} \\
\mathrm{MRI}>\mathrm{PET} / \mathrm{CT}^{\mathrm{b}}\end{array}$ & & \\
\hline $\begin{array}{l}\text { Ergul }^{9} \\
\text { Breast MRI, } \\
\text { Whole } \\
\text { body }\end{array}$ & $\mathrm{PET} / \mathrm{CT}$ & $\begin{array}{l}\text { MRI > PET/CT } \\
\text { PET/CT }>\text { MRI }^{\mathrm{b}}\end{array}$ & $\begin{array}{l}\mathrm{PET} / \mathrm{CT}>\mathrm{MRI}^{\mathrm{a}} \\
\mathrm{PET} / \mathrm{CT}>\mathrm{MRI}^{\mathrm{b}}\end{array}$ & & \\
\hline $\begin{array}{l}\text { Taneja }{ }^{43} \text { Breast } \\
\text { PET/MRI }\end{array}$ & & $\begin{array}{l}\mathrm{MRI}>\mathrm{PET}^{\mathrm{a}, \mathrm{b}} \\
\mathrm{PET}>\mathrm{MRI}^{\mathrm{b}}\end{array}$ & $\begin{array}{l}\mathrm{MRI}>\mathrm{PET}^{\mathrm{a}, \mathrm{b}} \\
\mathrm{MRI}=\mathrm{PET}^{\mathrm{b}}\end{array}$ & & $\mathrm{MRI}>\mathrm{PET}^{\mathrm{a}, \mathrm{b}}$ \\
\hline $\begin{array}{l}\text { van Nijnatten }{ }^{67} \\
\text { Whole body } \\
\text { (PET/CT) } \\
\text { Axilla } \\
\text { (PET/MRI) }\end{array}$ & & & $\begin{array}{l}\mathrm{PET} / \mathrm{MRI}>\mathrm{US} \\
\mathrm{PET} / \mathrm{MRI}>\mathrm{MRI} \\
\mathrm{PET} / \mathrm{MRI}> \\
\mathrm{PET} / \mathrm{CT}\end{array}$ & & \\
\hline $\begin{array}{l}\text { Jochelson }^{69} \\
\text { Whole body }\end{array}$ & & & & $\mathrm{MRI}>\mathrm{PET} / \mathrm{CT}^{\mathrm{a}}$ & \\
\hline $\begin{array}{l}\text { Melsaether }{ }^{44} \\
\text { Whole body }\end{array}$ & & & & & $\underset{\mathrm{CT}^{\mathrm{P}, \mathrm{b}}}{\mathrm{PET} / \mathrm{MRI}}>\mathrm{PET} /$ \\
\hline $\begin{array}{l}\text { Sawicki }{ }^{85} \\
\text { Whole body }\end{array}$ & & & & & $\begin{array}{l}\mathrm{PET} / \mathrm{MRI}>\mathrm{PET} / \\
\mathrm{CT}^{\mathrm{a}}\end{array}$ \\
\hline $\begin{array}{l}\text { Catalano } \\
\text { Whole body }\end{array}$ & & & & & $\begin{array}{c}\mathrm{PET} / \mathrm{MRI}>\mathrm{PET} / \\
\mathrm{CT}^{\mathrm{a}, \mathrm{b}} \\
\mathrm{PET} / \mathrm{MRI}^{\mathrm{M}}>\mathrm{PET} / \\
\mathrm{CT}^{\mathrm{b}, \mathrm{c}}\end{array}$ \\
\hline Heusner ${ }^{91}$ & & & & & $\mathrm{PET} / \mathrm{CT}>\mathrm{DWI}^{\mathrm{a}}$ \\
\hline
\end{tabular}


therapy, PET/MRI is a versatile imaging tool that can provide whole-body staging during a single exam; suggested imaging sequences are listed in Table 1 (Fig. 3). Although who requires whole-body PET-based imaging is not standardized, a study of untreated breast cancer patients by Groheux et $\mathrm{al}^{83}$ showed that PET/CT detects unsuspected metastatic disease in $2.3 \%$ of clinical stage IIA patients, who are predominantly patients with tumors between $2 \mathrm{~cm}$ and $5 \mathrm{~cm}$ and, less commonly, patients with tumors less than $2 \mathrm{~cm}$ but with axillary nodal disease, and that this percentage increases steadily up to $47.1 \%$ of clinical stage IIIC patients, who are patients with any tumor size who have involvement of an internal mammary node, a supraclavicular node, or at least 10 axillary nodes. ${ }^{83}$ In addition, PET/CT is used to assess for metastatic disease in treated breast cancer patients who present with new symptoms or with rising tumor markers. In terms of PETbased imaging, multiple studies have demonstrated improved sensitivity of whole-body PET/MRI over whole-body PET/CT in the context of breast cancer and other cancers (Table 2), including for detection of liver and bone metastases - the two most common sites of distant breast cancer spread. ${ }^{84}$ In a study of 242 breast cancer metastases in 51 patients, PET/MRI demonstrated significantly improved detection of 40 liver metastases compared with PET/CT $(P<0.001)$, and significantly improved detection of 107 bone metastases compared with PET/CT $(P=0.012)$; brain metastases were also identified by PET/MRI in five patients. ${ }^{44} \mathrm{Sim}-$ ilar findings of improved detection of osseous breast cancer metastases with PET/MRI vs. PET/CT were described in a series of 65 bone metastases in 17 patients with recurrent breast cancer by Sawicki et al. ${ }^{85}$ In a study by Catalano et al, PET/MRI identified significantly more breast cancer metastases to bone compared with PET/CT (141 vs. 90, $P<0.001$ ) in 25 patients. ${ }^{86}$ Catalano et al also reported significantly improved whole-body staging in 51 patients with invasive breast cancer using PET/MRI vs. PET/CT (50/51 vs. 38/51 correct, $P<0.01) .{ }^{87}$

Regarding pulmonary metastases, in the same study of 242 breast cancer metastases mentioned above, PET/CT showed a trend towards improved detection of 23 lung metastases compared with PET/MRI $(P=0.065) .{ }^{44}$ However, the clinical importance of lung lesions missed by PET/MRI is unclear. In a study of 208 patients with various primary malignancies (including 15 with breast cancer), 97\% of lung nodules \&le; $1 \mathrm{~cm}$ not identified on PET/MRI were stable or resolved on follow-up; in a single patient, three such lung nodules not seen by PET/MRI did progress. ${ }^{88}$

Finally, especially when looking for recurrences, it should be noted that while PET/MRI is sensitive to lesions throughout the body, dedicated breast MRI or prone breast PET/MRI is superior to supine whole-body PET/MRI, for breast lesions, likely due to tissue collapse in the supine position. In a study by Kong et al, only $4 / 10$ (40\%) subcentimeter breast cancers were seen on whole-body PET/MRI. ${ }^{49}$ In a study by Sasaki et al, primary breast cancers were seen in all 94 patients on dedicated prone breast/MRI, while whole-body PET-MRI did not identify primary breast cancers in $7 / 94$ (7\%) patients. ${ }^{89}$ Therefore, in patients with elevated tumor markers and negative whole-body imaging, consideration may be given to dedicated breast imaging. A comparison of PET/MRI with MRI and PET/CT for clinical tasks is provided in Table 3.

\section{CLINICAL RELEVANCE}

PET/MR is a promising flexible imaging tool that may be of use in dedicated breast exams and in whole-body exams. When used with multiple MRI parameters, breast PET/MRI has shown promise in reducing unnecessary biopsies that would be recommended based on their current standard DCE-MRI. ${ }^{50}$ However, the radiation dose and imaging, processing, and reading times associated with such an exam make it unlikely that this type of breast imaging will become part of our clinical routine. Instead, breast PET/MR may be more important before and during neoadjuvant therapy, where multiple layers of imaging parameters may eventually be converted into radiomic data that may lend increased precision to breast cancer treatments; and in local staging, where the improved evaluation of the axilla potentially afforded by PET/MRI may eventually preclude the need axillary lymph node tissue sampling. ${ }^{6,66}$ For breast cancer patients in need of whole-body staging or posttreatment surveillance, PET/MR outperforms PET/CT at a much lower radiation dose. ${ }^{44}$ Here, the inclusion of DWI in PET/MRI protocols adds sensitivity to whole-body exams, to which PET adds specificity.

\section{REFERENCES}

1. Groheux D, Espié M, Giacchetti S, Hindié E. Performance of FDG PET/CT in the clinical management of breast cancer. Radiology 2013;266: 388-405.

2. Yamamoto Y, Ozawa Y, Kubouchi K, Nakamura S, Nakajima Y, Inoue T. Comparative analysis of imaging sensitivity of positron emission mammography and whole-body PET in relation to tumor size. Clin Nucl Med 2015;40:21-25.

3. Berg WA, Zhang Z, Lehrer D, et al. ACRIN 6666 Investigators. Detection of breast cancer with addition of annual screening ultrasound or a single screening MRI to mammography in women with elevated breast cancer risk. JAMA 2012;307:1394-1404.

4. Kuhl C, Weigel S, Schrading S, et al. Prospective multicenter cohort study to refine management recommendations for women at elevated familial risk of breast cancer: the EVA trial. J Clin Oncol 2010;28: 1450-1457

5. American College of Radiology: ACR practice guideline for the performance of magnetic resonance imaging (MRI) of the breast. Practice guidelines and technical standards. Reston, VA: American College of Radiology; 2013.

6. Botsikas D, Kalovidouri A, Becker $M$, et al. Clinical utility of 18F-FDG-PET/MR for preoperative breast cancer staging. Eur Radiol 2016;26:2297-2307. 
7. Heusner TA, Hahn S, Jonkmanns C, et al. Diagnostic accuracy of fused positron emission tomography/magnetic resonance mammography: initial results. Br J Radiol 2011;84:126-135.

8. Grueneisen J, Nagarajah J, Buchbender C, et al. Positron emission tomography/magnetic resonance imaging for local tumor staging in patients with primary breast cancer: a comparison with positron emission tomography/computed tomography and magnetic resonance imaging. Invest Radiol 2015;50:505-513.

9. Ergul N, Kadioglu H, Yildiz S, et al. Assessment of multifocality and axillary nodal involvement in early-stage breast cancer patients using 18F-FDG PET/CT compared to contrast-enhanced and diffusion-weighted magnetic resonance imaging and sentinel node biopsy. Acta Radiol 2015;56: 917-923.

10. Moy L, Ponzo F, Noz ME, et al. Improving specificity of breast MRI using prone PET and fused MRI and PET 3D volume datasets. J Nucl Med 2007;48:528-537.

11. Moy L, Noz ME, Maguire GQ, et al. Role of fusion of prone FDG-PET and magnetic resonance imaging of the breasts in the evaluation of breast cancer. Breast J 2010;16:369-376.

12. Garcia-Velloso MJ, Ribelles MJ, Rodriguez M, et al. MRI fused with prone FDG PET/CT improves the primary tumour staging of patients with breast cancer. Eur Radiol 2017;27:3190-3198.

13. Domingues RC, Carneiro MP, Lopes FC, da Fonseca LM, Gasparetto EL. Whole-body MRI and FDG PET fused images for evaluation of patients with cancer. AJR Am J Roentgenol 2009;192:1012-1020.

14. Ziegler SI, Pichler BJ, Boening G, et al. A prototype high-resolution animal positron tomograph with avalanche photodiode arrays and LSO crystals. Eur J Nucl Med 2001:28:136-143.

15. Zaidi H, Montandon ML, Slosman DO. Magnetic resonance imaging-guided attenuation and scatter corrections in three-dimensional brain positron emission tomography. Med Phys 2003;30:937-948.

16. Hofmann M, Bezrukov I, Mantlik F, et al. MRI-based attenuation correction for whole-body PET/MRI: quantitative evaluation of segmentationand atlas-based methods. J Nucl Med 2011;52:1392-1399.

17. Aklan B, Paulus DH, Wenkel E, et al. Toward simultaneous PET/MR breast imaging: systematic evaluation and integration of a radiofrequency breast coil. Med Phys 2013;40:024301

18. Dregely I, Lanz T, Metz S, et al. A 16-channel MR coil for simultaneous PET/MRI in breast cancer. Eur Radiol 2015;25:1154-1161.

19. Pace L, Nicolai E, Luongo, et al. Comparison of whole-body PET/CT and PET/MRI in breast cancer patients: lesion detection and quantitation of $18 \mathrm{~F}$-deoxyglucose uptake in lesions and in normal organ tissues. Eur J Radiol 2014;83:289-296.

20. Pujara AC, Raad RA, Ponzo F, et al. Standardized uptake values from $\mathrm{PET} / \mathrm{MRI}$ in metastatic breast cancer: an organ-based comparison with PET/CT. Breast J 2016;22:264-273.

21. Al-Nabhani KZ, Syed R, Michopoulou S, et al. Qualitative and quantitative comparison of PET/CT and PET/MR imaging in clinical practice. J Nucl Med 2014;55:88-94.

22. Drzezga A, Souvatzoglou $M$, Eiber $M$, et al. First clinical experience with integrated whole-body PET/MR: comparison to $\mathrm{PET/CT}$ in patients with oncologic diagnoses. J Nucl Med 2012;53:845-855.

23. Heusch P, Nensa F, Schaarschmidt B, et al. Diagnostic accuracy of whole-body PET/MRI and whole-body PET/CT for TNM staging in oncology. Eur J Nucl Med Mol Imaging 2015;42:42-48.

24. Huellner MW, Appenzeller P, Kuhn FP, et al. Whole-body nonenhanced PET/MR versus PET/CT in the staging and restaging of cancers: preliminary observations. Radiology 2014;273:859-869.

25. Bos R, van Der Hoeven JJ, van Der Wall E, et al. Biologic correlates of (18)fluorodeoxyglucose uptake in human breast cancer measured by positron emission tomography. J Clin Oncol 2002;20:379-387.

26. Gil-Rendo A, Martínez-Regueira F, Zornoza G, García-Velloso MJ, Beorlegui C, Rodriguez-Spiteri N. Association between [18F]fluorodeoxyglucose uptake and prognostic parameters in breast cancer. $\mathrm{Br} \mathrm{J}$ Surg 2009;96:166-170.
27. Kumar $R$, Chauhan A, Zhuang $H$, Chandra $P$, Schnall M, Alavi A. Clinicopathologic factors associated with false negative FDG-PET in primary breast cancer. Breast Cancer Res Treat 2006;98:267-274.

28. Kim MY, Cho N, Chang JM, et al. Mammography and ultrasonography evaluation of unexpected focal 18F-FDG uptakes in breast on PET/CT. Acta Radiol 2012;53:249-254.

29. Toney LK, Lam DL, Rahbar H. Drug injection-related fat necrosis of the breast with FDG PET-CT uptake. Radiol Case Rep 2015;10:12-17.

30. Piccardo A, Puntoni M, Morbelli S, et al. 18F-FDG PET/CT is a prognostic biomarker in patients affected by bone metastases from breast cancer in comparison with 18F-NaF PET/CT. Nuklearmedizin 2015;54:163-172.

31. Jambor I, Kuisma A, Ramadan S, et al. Prospective evaluation of planar bone scintigraphy, SPECT, SPECT/CT, 18F-NaF PET/CT and whole body 1.5T MRI, including DWI, for the detection of bone metastases in high risk breast and prostate cancer patients: SKELETA clinical trial. Acta Oncol 2016;55:59-67.

32. Czernin J, Satyamurthy N, Schiepers C. Molecular mechanisms of bone 18F-NaF deposition. J Nucl Med 2010;51:1826-1829.

33. Katzenellenbogen JA. Designing steroid receptor-based radiotracers to image breast and prostate tumors. J Nucl Med 1995;36:8S-13S.

34. Gemignani ML, Patil S, Seshan VE, et al. Feasibility and predictability of perioperative PET and estrogen receptor ligand in patients with invasive breast cancer. J Nucl Med 2013;54:1697-1702.

35. Dijkers EC, Oude Munnink TH, Kosterink JG, et al. Biodistribution of 89Zr-trastuzumab and PET imaging of HER2-positive lesions in patients with metastatic breast cancer. Clin Pharmacol Ther 2010;87:586-592.

36. Gaykema SB, Schröder CP, Vitfell-Rasmussen J, et al. 89Zr-trastuzumab and $89 \mathrm{Zr}$-bevacizumab PET to evaluate the effect of the HSP90 inhibitor NVP-AUY922 in metastatic breast cancer patients. Clin Cancer Res 2014; 20:3945-3954.

37. Gaykema SB, de Jong JR, Perik PJ, et al. (111)In-trastuzumab scintigraphy in HER2-positive metastatic breast cancer patients remains feasible during trastuzumab treatment. Mol Imaging 2014;13.

38. Axelson $H$, Fredlund $E$, Ovenberger $M$, Landberg $G$, Påhlman $S$. Hypoxia-induced dedifferentiation of tumor cells_a mechanism behind heterogeneity and aggressiveness of solid tumors. Semin Cell Dev Biol $2005 ; 16: 554-563$

39. Jögi A, Øra I, Nilsson $H$, et al. Hypoxia alters gene expression in human neuroblastoma cells toward an immature and neural crest-like phenotype. Proc Natl Acad Sci U S A 2002;99:7021-7026.

40. Nordsmark M, Bentzen SM, Rudat V, et al. Prognostic value of tumor oxygenation in 397 head and neck tumors after primary radiation therapy. An international multi-center study. Radiother Oncol 2005;77: 18-24.

41. Cheng J, Lei L, Xu J, et al. 18F-fluoromisonidazole PET/CT: a potential tool for predicting primary endocrine therapy resistance in breast cancer. J Nucl Med 2013;54:333-340.

42. Ostenson J, Pujara AC, Mikheev A, et al. Voxelwise analysis of simultaneously acquired and spatially correlated (18) F-fluorodeoxyglucose (FDG)-PET and intravoxel incoherent motion metrics in breast cancer. Magn Reson Med 2017;78:1147-1156.

43. Taneja S, Jena A, Goel R, Sarin R, Kaul S. Simultaneous whole-body 18F-FDG PET-MRI in primary staging of breast cancer: a pilot study. Eur J Radiol 2014;83:2231-2239.

44. Melsaether AN, Raad RA, Pujara AC, et al. Comparison of whole-body (18)F FDG PET/MR imaging and whole-body (18)F FDG PET/CT in terms of lesion detection and radiation dose in patients with breast cancer. Radiology 2016;281:193-202

45. Kuhl CK, Strobel K, Bieling H, Leutner C, Schild HH, Schrading S. Supplemental breast MR imaging screening of women with average risk of breast cancer. Radiology 2017;283:361-370.

46. Bitencourt AG, Lima EN, Chojniak $R$, Marques EF, Souza JA, Andrade WP, Guimarães MD. Multiparametric evaluation of breast lesions using PET-MRI: initial results and future perspectives. Medicine (Baltimore) 2014;93:e115. 
47. Avril N, Rosé CA, Schelling $M$, et al. Breast imaging with positron emission tomography and fluorine-18 fluorodeoxyglucose: use and limitations. J Clin Oncol 2000;18:3495-3502.

48. Jung NY, Kim SH, Kim SH, et al. Effectiveness of breast MRI and (18) F-FDG PET/CT for the preoperative staging of invasive lobular carcinoma versus ductal carcinoma. J Breast Cancer 2015;18:63-72.

49. Magometschnigg HF, Baltzer PA, Fueger B, et al. Diagnostic accuracy of (18)F-FDG PET/CT compared with that of contrast-enhanced MRI of the breast at 3 T. Eur J Nucl Med Mol Imaging 2015;42:1656-1665.

50. Kong EJ, Chun KA, Bom HS, Lee J, Lee SJ, Cho IH. Initial experience of integrated PET/MR mammography in patients with invasive ductal carcinoma. Hell J Nucl Med 2014;17:171-176.

51. Pinker $K$, Bogner W, Baltzer $P$, et al. Improved differentiation of benign and malignant breast tumors with multiparametric 18fluorodeoxyglucose positron emission tomography magnetic resonance imaging: a feasibility study. Clin Cancer Res 2014;20:3540-3549.

52. Jena A, Taneja S, Singh A, Negi P, Mehta SB, Sarin R. Role of pharmacokinetic parameters derived with high temporal resolution DCE MRI using simultaneous PET/MRI system in breast cancer: A feasibility study. Eur J Radiol 2017;86:261-266.

53. Amarnath J, Sangeeta T, Mehta SB. Role of quantitative pharmacokinetic parameter (transfer constant: $\mathrm{K}($ trans)) in the characterization of breast lesions on MRI. Indian J Radiol Imaging 2013;23:19-25.

54. Margolis NE, Moy L, Sigmund EE, et al. Assessment of aggressiveness of breast cancer using simultaneous 18F-FDG-PET and DCE-MRI: preliminary observation. Clin Nucl Med 2016;41:e355-361.

55. Catalano OA, Horn GL, Signore A, et al. PET/MR in invasive ductal breast cancer: correlation between imaging markers and histological phenotype. Br J Cancer 2017;116:893-902.

56. An YS, Kang DK, Jung YS, Han S, Kim TH. Tumor metabolism and perfusion ratio assessed by 18 F-FDG PET/CT and DCE-MRI in breast cancer patients: Correlation with tumor subtype and histologic prognostic factors. Eur J Radiol 2015;84:1365-1370.

57. Kim TH, Yoon JK, Kang DK, et al. Correlation between F-18 fluorodeoxyglucose positron emission tomography metabolic parameters and dynamic contrast-enhanced MRI-derived perfusion data in patients with invasive ductal breast carcinoma. Ann Surg Oncol 2015;22:3866-3872.

58. Kitajima K, Yamano T, Fukushima K, et al. Correlation of the SUVmax of FDG-PET and ADC values of diffusion-weighted MR imaging with pathologic prognostic factors in breast carcinoma. Eur J Radiol 2016;85: 943-949.

59. Karan B, Pourbagher A, Torun N. Diffusion-weighted imaging and (18) F-fluorodeoxyglucose positron emission tomography/computed tomography in breast cancer: Correlation of the apparent diffusion coefficient and maximum standardized uptake values with prognostic factors. J Magn Reson Imaging 2016;43:1434-1444.

60. Baba S, Isoda T, Maruoka Y, et al. Diagnostic and prognostic value of pretreatment SUV in 18F-FDG/PET in breast cancer: comparison with apparent diffusion coefficient from diffusion-weighted MR imaging. J Nucl Med 2014;55:736-742.

61. Choi BB, Kim SH, Kang BJ, et al. Diffusion-weighted imaging and FDG PET/CT: predicting the prognoses with apparent diffusion coefficient values and maximum standardized uptake values in patients with invasive ductal carcinoma. World J Surg Oncol 2012;10:126.

62. Pahk K, Kim S, Choe JG. Early prediction of pathological complete response in luminal $\mathrm{B}$ type neoadjuvant chemotherapy-treated breast cancer patients: comparison between interim 18F-FDG PET/CT and MRI. Nucl Med Commun 2015;36:887-891.

63. Mei-rong Zhou, Zhong-hua Tang, Jing Li, et al. Clinical and pathologic features of multifocal and multicentric breast cancer in Chinese women: a retrospective cohort study. J Breast Cancer 2013;16:77-83.

64. Lang Z, Wu Y, Li C, Li X, Wang X, Qu G. Multifocal and multicentric breast carcinoma: a significantly more aggressive tumor than unifocal breast cancer. Anticancer Res 2017;37:4593-4598.
65. Bae MS, Chang JM, Cho N, Han W, Ryu HS, Moon WK. Association of preoperative breast MRI features with locoregional recurrence after breast conservation therapy. Acta Radiol 2018;59:409-417.

66. Goorts B, Vöö S, van Nijnatten TJA. Hybrid ${ }^{18}$ F-FDG PET/MRI might improve locoregional staging of breast cancer patients prior to neoadjuvant chemotherapy. Eur J Nucl Med Mol Imaging 2017;44:1796-1805.

67. van Nijnatten TJA, Goorts B, Vöö S. Added value of dedicated axillary hybrid 18F-FDG PET/MRI for improved axillary nodal staging in clinically node-positive breast cancer patients: a feasibility study. Eur J Nucl Med Mol Imaging 2018;45:179-186.

68. Noushi F, Spillane AJ, Uren RF, Gebski V. Internal mammary lymph node metastasis in breast cancer: predictive models to assist with prognostic influence. Breast 2011;20:278-283.

69. Jochelson MS, Lebron L, Jacobs SS, et al. Detection of internal mammary adenopathy in patients with breast cancer by PET/CT and MRI. AJR Am J Roentgenol 2015;205:899-904.

70. Greenwood HI, Freimanis RI, Carpentier BM, Joe BN. Clinical breast magnetic resonance imaging: technique, indications, and future applications. Semin Ultrasound CT MR 2018;39:45-59.

71. Kinoshita T, Odagiri K, Andoh K, et al. Evaluation of small internal mammary lymph node metastases in breast cancer by MRI. Radiat Med 1999; 17:189-193.

72. Gillies RJ, Kinahan PE, Hricak H. Radiomics: images are more than pictures, they are data. Radiology 2016;278:563-577.

73. Drukker K, Li H, Antropova N, Edwards A, Papaioannou J, Giger ML. Most-enhancing tumor volume by MRI radiomics predicts recurrence-free survival "early on" in neoadjuvant treatment of breast cancer. Cancer Imaging 2018;18:12.

74. Hylton NM, Blume JD, Bernreuter WK, et al. ACRIN 6657 Trial Team and I-SPY 1 TRIAL Investigators. Locally advanced breast cancer: MR imaging for prediction of response to neoadjuvant chemotherapy-results from ACRIN 6657/I-SPY TRIAL. Radiology 2012;263:663-672.

75. Cho N, Im SA, Cheon GJ, et al. Integrated (18)F-FDG PET/MRI in breast cancer: early prediction of response to neoadjuvant chemotherapy. Eur J Nucl Med Mol Imaging 2018;45:328-339.

76. Wang J, Shih TT, Yen RF. Multiparametric evaluation of treatment response to neoadjuvant chemotherapy in breast cancer using integrated PET/MR. Clin Nucl Med 2017;42:506-513.

77. Pengel KE, Koolen BB, Loo CE, et al. Combined use of 18F-FDG PET/CT and $\mathrm{MRI}$ for response monitoring of breast cancer during neoadjuvant chemotherapy. Eur J Nucl Med Mol Imaging 2014;41:1515-1524.

78. An YY, Kim SH, Kang BJ, Lee AW. Treatment response evaluation of breast cancer after neoadjuvant chemotherapy and usefulness of the imaging parameters of MRI and PET/CT. J Korean Med Sci 2015;30: 808-815.

79. Lim I, Noh WC, Park J, et al. The combination of FDG PET and dynamic contrast-enhanced MRI improves the prediction of disease-free survival in patients with advanced breast cancer after the first cycle of neoadjuvant chemotherapy. Eur J Nucl Med Mol Imaging 2014;41:1852-1860.

80. Tateishi U, Miyake M, Nagaoka T, et al. Neoadjuvant chemotherapy in breast cancer: prediction of pathologic response with PET/CT and dynamic contrast-enhanced MR imaging-prospective assessment. Radiology 2012;263:53-63.

81. Jacobs MA, Ouwerkerk R, Wolff AC, et al. Monitoring of neoadjuvant chemotherapy using multiparametric, $23 \mathrm{Na}$ sodium MR, and multimodality (PET/CT/MRI) imaging in locally advanced breast cancer. Breast Cancer Res Treat 2011;128:119-126.

82. Cho N, Im SA, Kang KW, et al. Early prediction of response to neoadjuvant chemotherapy in breast cancer patients: comparison of single-voxel (1) $\mathrm{H}$-magnetic resonance spectroscopy and (18)F-fluorodeoxyglucose positron emission tomography. Eur Radiol 2016;26:2279-2290.

83. Groheux D, Hindié $E$, Delord $M$, et al. Prognostic impact of (18) FDG-PET-CT findings in clinical stage III and IIB breast cancer. J Nat Cancer Inst 2012;104:1879-1887. 
84. Plecha DM, Faulhaber P. PET/MRI of the breast. Eur J Radiol 2017;94 A26-A34.

85. Sawicki LM, Grueneisen J, Schaarschmidt BM, et al. Evaluation of 18F-FDG PET/MRI, 18F-FDG PET/CT, MRI, and CT in whole-body staging of recurrent breast cancer. Eur J Radiol 2016;85:459-465.

86. Catalano OA, Nicolai E, Rosen BR, et al. Comparison of CE-FDG-PET/CT with CE-FDG-PET/MR in the evaluation of osseous metastases in breast cancer patients. Br J Cancer 2015;112:1452-1460.

87. Catalano OA, Daye D, Signore A. Staging performance of whole-body DWI, PET/CT and PET/MRI in invasive ductal carcinoma of the breast. Int J Oncol 2017;51:281-288.

88. Raad RA, Friedman KP, Heacock L, Ponzo $F$, Melsaether A Chandarana $\mathrm{H}$. Outcome of small lung nodules missed on hybrid PET/MRI in patients with primary malignancy. J Magn Reson Imaging 2016; 43:504-511.

89. Sasaki M, Tozaki M, Kubota $K$, et al. Simultaneous whole-body and breast 18F-FDG PET/MRI examinations in patients with breast cancer: a comparison of apparent diffusion coefficients and maximum standardized uptake values. Jpn J Radiol 2018;36:122-133.

90. Riola-Parada C, García-Cañamaque L, Pérez-Dueñas V, Garcerant-Tafur M, Carreras-Delgado JL. Simultaneous. PET/MRI vs. PET/CT in oncology. A systematic review. Rev Esp Med Nucl Imagen Mol 2016;35:306-312.

91. Heusner TA, Kuemmel S, Koeninger A, et al. Diagnostic value of diffusion-weighted magnetic resonance imaging (DWI) compared to FDG $\mathrm{PET} / \mathrm{CT}$ for whole-body breast cancer staging. Eur J Nucl Med Mol Imaging 2010;37:1077-1086.

92. Grueneisen J, Sawicki LM, Wetter A. Evaluation of PET and MR datasets in integrated 18F-FDG PET/MRI: A comparison of different MR sequences for whole-body restaging of breast cancer patients. Eur J Radiol 2017;89:14-19.

93. Beiderwellen K, Huebner M, Heusch $\mathrm{P}$, et al. Whole-body [18F]FDG $\mathrm{PET} / \mathrm{MRI}$ vs. PET/CT in the assessment of bone lesions in oncological patients: initial results. Eur Radiol 2014;24:2023-2030.

94. Eiber M, Takei T, Souvatzoglou M, et al. Performance of whole-body integrated 18F-FDG PET/MR in comparison to PET/CT for evaluation of malignant bone lesions. J Nucl Med 2014;55:191-197.

95. Jeong JH, Cho IH, Kong EJ, Chun KA. Evaluation of Dixon sequence on hybrid PET/MR compared with contrast-enhanced PET/CT for PET-positive lesions. Nucl Med Mol Imaging 2014;48:26-32.

96. Schäfer JF, Gatidis S, Schmidt H. Simultaneous whole-body PET/MR imaging in comparison to $\mathrm{PET/CT}$ in pediatric oncology: initial results. Radiology 2014;273:220-231. 